\title{
Modelling of air pollutants released from highway traffic in Hungary
}

\author{
Gy. Baranka \\ Hungarian Meteorological Service, Hungary
}

\begin{abstract}
The aim of study is to determine the $\mathrm{CO}$ and $\mathrm{NO}_{2}$ concentrations near Hungarian motorways. The expressway network in Hungary is comprised of 650 kilometres of motorway, 205 kilometres of clearways and highways as well as 188 kilometres of junction point sections. The CALINE4 dispersion model developed by the California Department of Transportation for predicting $\mathrm{CO}, \mathrm{NO}_{2}$ concentrations near roadways was adapted at Hungarian Meteorological Service. The dispersion equation is based on an analytic solution of the Gaussian diffusion equation for a finite line source. This model was combined with a "mixing zone" model segment. The "mixing zone" is defined as the region over the road characterized by uniform emissions and turbulence. The model treats traffic as an infinite line source divided into a series of elements located perpendicular to the wind direction. Vertical dispersion parameters take into consideration both thermal and mechanical turbulence caused by vehicles. A CALINE4 roadway link is assigned an equivalent line source strength based on the product of a fleet averaged vehicle emission factor (grams of pollutant per vehicle per mile traveled) and vehicle flow rate (vehicles per hour). The CALINE4 requires relatively minimal input from the user. Input data are traffic volume, emission factors, roadway geometry, wind speed and direction, ambient air temperature, mixing height, atmospheric stability class and coordinate of receptors. Using CALINE4 dispersion model 1-hour and 8-hour averages CO and $\mathrm{NO}_{2}$ concentrations have been determined at the receptors within 500 meters of the Hungarian motorways and around the intersection links.
\end{abstract}

Keywords: emission of road traffic, turbulence, diffusion processes, CALINE4 model, spatial distribution. 


\section{Introduction}

The aim of study is to investigate the possible impact of scenarios (including investment of shopping stores, ring roads and the variation of driving customs and the vehicle fleet mix) on air quality and to determine the number of exceedence of air quality limit values near motorways. Using dispersion models connected to the estimation of road emission for future years and to a weather forecast model the variation of air quality can be predicted. The ambient air quality effects of traffic emissions near Hungarian motorways were evaluated using the CALINE4 dispersion model.

\section{Hungarian $\mathrm{CO}$ and $\mathrm{NO}_{\mathrm{x}}$ emissions from mobile sources}

In Hungary the expressway network is comprised of 650 kilometres of motorway, 205 kilometres of clearways and highways (which are comprised of highways serving as expressways, highways with expressway features later converted to expressways, and highway sections with expressway features) as well as 188 kilometres of junction point sections, 52 kilometres of roads leading to rest areas, and 106 rest areas.

NOx emission from road traffic in Hungary

$\mathrm{kt}$

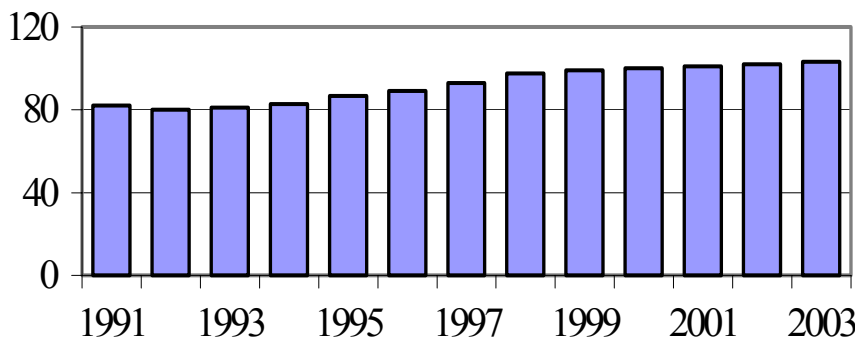

Figure 1: $\quad$ NOx emission from road traffic calculated by Merétei [4].

The Hungarian $\mathrm{CO}$ and NOx emissions from mobile sources have been investigated by Merétei [4]. Emission of nitrogen oxides from road traffic was continuously increased, (fig. 1), while the emission of carbon monoxide from the same sources was decreased during the last twenty years (fig. 2). NOx emission from road traffic is growing (growing rate is $20 \%$ ) due to the increasing of travelled kilometers by cars and duty. In the same time NOx emission of the European members was decreased by $20 \%$ due to the application of three steps catalizator in the new cars and the changes of the compound of the fuel. In general for EU-15 energy consumption for road traffic has been increased since 1990, but energy efficiency has been improved by 10\% since 1990 (Ntziachristos et al [5]). 
$\mathrm{kt}$

\section{COemission from road traffic in Hungary}

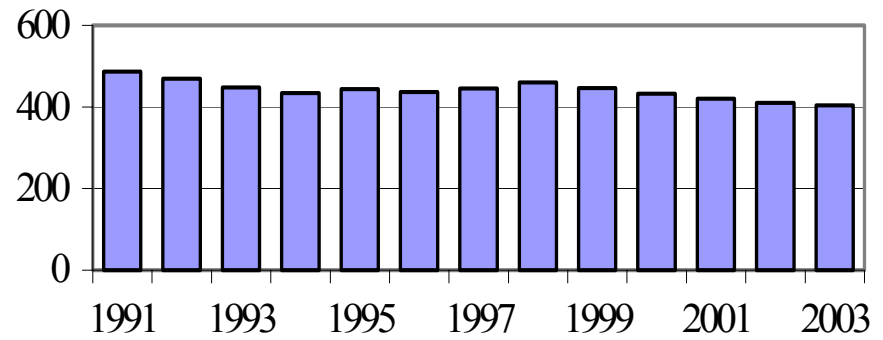

Figure 2: $\quad \mathrm{CO}$ emission from road traffic calculated by Merétei [4].

Source emissions are a function of both the vehicle emissions factors and the vehicle activity (usually measured in vehicle kilometers travelled). The vehicle emission factors can differ greatly depending on the type of road, vehicle fleet mix, and traffic flow encountered. As a result, emissions factors were determined specifically for each roadside location to ensure that the appropriate input was used for the modelling of subsequent roadway emissions. These site-specific emissions factors were then combined with the vehicle kilometers travelled data to give a total emission rate for the road.

\section{Diffusion processes in roadway modelling}

The total diffusion is divided into primary diffusion affected by the traffic and the diffusion caused by ambient meteorological conditions. Contaminants outcome from tailpipe take part in primary process, on one hand the thermal turbulence caused by differential surface heating and by the buoyant exhausted plume creates eddy movements, on the other hand mechanical turbulence from wind flow and the traffic wake induce turbulence. Thermal influences interact with mechanical effects. There are interactions between the ambient wind speed, exhaust velocities of the tailpipe emissions and the traffic wake-induced turbulence. Primary turbulence is meaningful only in stagnant conditions (especially in case of cold-running) otherwise the atmospheric turbulence dominates the process. The plume is transported with the wind speed at the emission height. Behind a vehicle due to the thermal and mechanical turbulence a well-mixed zone can be occurred.

In general micro scale (characteristic lengths below $1 \mathrm{~km}$ ) airflow is very complex, as it depends strongly on the detailed surface characteristics (i.e. form of buildings, their orientation with regard to the wind direction etc.). Although thermal effects may contribute to the generation of these flows, they are mainly determined by hydrodynamic effects (e.g. flow channelling, roughness effects), which have to be described well in an appropriate simulation model. In view of the complex nature of such effects, local scale dispersion phenomena (which are to a large extent associated with micro scale atmospheric processes) are mainly 
described with robust "simple" models in the case of practical applications, such as mobile source models.

\section{Description of CALINE4 model}

CALINE4 (Benson [1]) is a dispersion model for predicting air pollution concentrations near roadways. It is the last in a series of line source air quality models developed by the California Department of Transportation (Caltrans). CALINE4 is a Gaussian dispersion model specifically designed to evaluate air quality impacts of roadway projects. Each roadway link analysed in the model is treated as a sequence of short segments. Each segment of a roadway link is treated as separate emission source producing a plume of pollutants, which disperses downwind. Pollutant concentrations at any specific location are calculated using the total contribution from overlapping pollution plumes originating from the sequence of roadway segments. Given source strength, meteorology and site geometry, CALINE4 can predict carbon monoxide, nitrogen dioxide and suspended particle concentrations for receptors located within 500 meters of the roadway. It also has special options for modelling air quality near intersections, street canyons and parking facilities.

CALINE4 uses mixing zone concept. The model treats the region directly over the highway as a zone of uniform emissions and turbulence. This is designated as the mixing zone, and is defined as the region over the travelled way (traffic lanes not including shoulders) plus three meters on either side. The additional width accounts for the initial horizontal dispersion imparted to pollutants by the vehicle wake. Within the mixing zone, the mechanical turbulence created by moving vehicles and the thermal turbulence created by hot vehicle exhaust is assumed to be the dominant depressive mechanisms.

Concentrations of relatively inert pollutants such as carbon monoxide and suspended particle concentrations have been predicted, and Discrete Parcel Method chemical subrutin has been used to determine the nitrogen dioxide concentration in a Gaussian plume. Discrete Parcel Method uses the cycle NO$\mathrm{O}_{3}-\mathrm{NO}_{2}$ solved analytically by Benson [1]. The processes associated with the expanding Gaussian plume and NOx-chemistry has been presented by Hanrahan [2]. The influence of plume dilution has been accounted according to the receptor oriented Discrete Parcel Method (Härkönen et al [3]), which is a modified version of the original method.

Historically, the CALINE series of models required relatively minimal input from the user. While CALINE4 uses more input parameters than its predecessors, it must still be considered an extremely easy model to implement.

\section{Results}

Using CALINE4 dispersion model hourly and 8-hour average concentrations can be obtained. The $\mathrm{CO}$ and $\mathrm{NO}_{2}$ concentrations have been calculated at $100 \mathrm{~m}$ away from road axis for Hungarian motorway network. During worst-case meteorology $\mathrm{NO}_{2}$ concentration is shown in fig. 3. Worst-case meteorology input 
is the combination of the worst wind speed, wind direction, stability class. The highest concentrations occur around Budapest. It can be explained by arterial roads structure in Hungary and by urban sprawling.

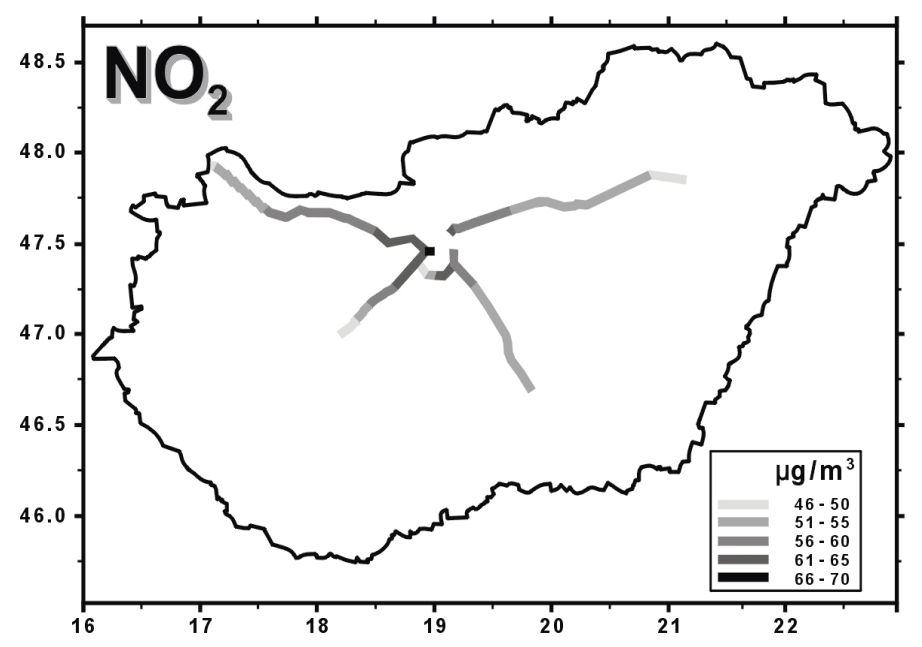

Figure 3: Worst-case 1-hour $\mathrm{NO}_{2}$ level at $100 \mathrm{~m}$ away from road axis.

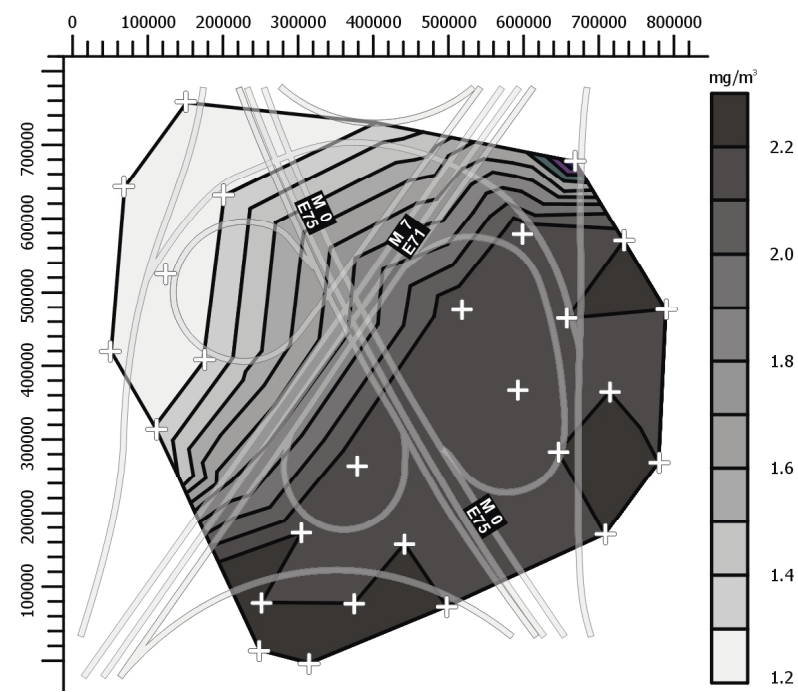

Figure 4: Hourly average of $\mathrm{CO}$ concentration around the intersection link No. M7 and M0.

CALINE4 model provides possibility to predict air pollutants near intersections. Spatial distributions of hourly average $\mathrm{CO}$ and $\mathrm{NO}_{2}$ concentrations 
are shown around an intersection near Budapest in fig. 4 and fig. 5. The distance between receptors (indicated by cross in figures) is $100 \mathrm{~m}$. Air pollutants are transported by the most frequent airflow to SW direction. At this intersection the traffic of motorway M7 is dominant.

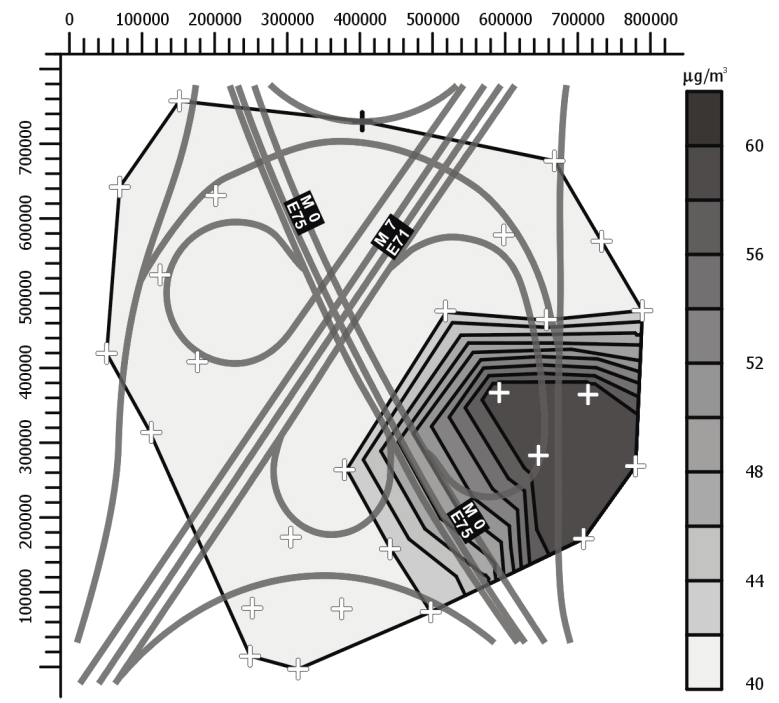

Figure 5: Hourly average of $\mathrm{NO}_{2}$ concentration around the intersection link No. M7 and M0.

Using dispersion models connected to the estimation of road emission for future years and to weather prediction models the variation of air quality can be obtained on a given area. With the aid of this project we would like to develop an integrated system of meteorological and dispersion models to calculate and visualize forecasted air quality situation near crowded roads. During the further research the ability and the limitation of coupling of dispersion model (e.g. CALINE4) on mesoscale forecasting model (e.g. WRF) will be examined for air pollution and emergency forecasting purposes.

\section{References}

[1] Benson, P. E. CALINE4 a dispersion model for predicting air pollution concentrations near roadways. California Department of Transportation. Sacramento, CA. California Department of Transportation. 1989.

[2] Hanrahan, P.L. The plume volume molar ratio for determining $\mathrm{NO} 2 / \mathrm{NOx}$ ratios in modelling - Part I: Methodology. J. Air \& Waste Manage. Assoc. 49, pp. 1324-1331, 1999.

[3] Härkönen, J., Valkonen, E., Kukkonen, J., Rantakrans, E., Lahtinen, K., Karppinen, A. and Jalkanen, L. A model for the dispersion of pollution from 
a road network. Finnish Meteorological Institute, Publications of Air Quality 23, Helsinki, 34 p. 1996.

[4] Merétei T. (editor) Determination of transport emission in Hungary (in Hungarian) Institute for Transport Sciences Non-profit LTD. Budapest 2006.

[5] Ntziachristos, L., Tourlou, P. M., Samaras Z., Geivanidis S. and Andrias A. National and central estimates for air emissions from road transport, Technical report 74, European Topic Centre on Air and Climate Change, 2002 